\title{
Teaching Evidence-Based Practice To Undergraduate Nursing Students: Overcoming Obstacles
}

Sharon D. Martin, (E-mail: smartin@sjcme.edu), Saint Joseph’s College of Maine

\begin{abstract}
Evidence-based practice is highly valued in health care literature at this time. But research suggests that U.S. RNs face many obstacles when implementing evidence-based practice including a lack of value for research in practice (Pravikoff et al, 2005). Additional obstacles may exist for traditional U.S. BSN nursing students who may not value the importance of learning about evidence-based practice principles or of implementing evidence-based practice in the clinical setting. If we are to improve the use of evidence-based practice among U.S. RNs, learning and valuing the process must begin during the basic nursing educational program.
\end{abstract}

This presentation outlines classroom research designed to uncover the specific obstacles to learning and implementing evidence-based practice described by traditional BSN students at a small, private, Catholic college just before they complete the final clinical internship before graduation. Several teaching strategies were designed to address the obstacles students described. A post-internship survey of the same students determined the effectiveness of the various teaching strategies. Recommendations for future research and for teaching strategies to enhance the learning and valuing of evidence-based practice among traditional U.S. BSN students are offered.

\section{RESEARCH SUMMARY}

\section{Problem}

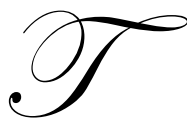

eaching traditional undergraduate BSN students to appreciate, understand, and apply Evidence-based Practice (research \& clinical practice guidelines) is a challenge. When asked why they do not use EBP (paraphrased). in clinical the most common reply is "lack of time" followed by "I'm not sure where to find it"

Our usual teaching approach for EBP is:

- $\quad$ identify a patient problem

- $\quad$ put it into PICO format

- $\quad$ identify MeSH terms

- $\quad$ do an extensive literature search

- $\quad$ analyze the results

- $\quad$ implement the findings into clinical practice

- evaluate the outcome 
What if we taught a shorter process? Would students respond more favorably?

\section{Research Question}

Would undergrad BSN students report a higher rate of using research and clinical practice guidelines clinically if instructed via a different, less time consuming process? That is,

- $\quad$ go directly to the National Guideline Clearinghouse at www.guideline.gov

- $\quad$ identify an applicable Clinical Practice Guideline

- $\quad$ implement the findings into clinical practice

- $\quad$ evaluate the outcome

\section{Hypothesis}

Senior traditional BSN students at our small, rural Catholic college will report a significantly more favorable response to and use of EBP (especially clinical practice guidelines) if taught via the shorter process vs. the longer process.

\section{Methods}

Because of its size the senior nursing class is naturally divided into two sections taught by two instructors. The section division was based upon where the student wished to go for clinical internship and was unrelated to the research question. The instructor of the control group $(n=16)$ was blind to the exact nature of the different teaching process used with the experimental group $(n=17)$ but aware that a different process was being used.

Thus, the control group was taught to use the traditional EBP method while the experimental group was taught to use the shorter method.

Both groups of students completed the same Likert-like EBP Survey (see attached) at the beginning of the semester and at the end of the semester (pre-post design). Questions explored student's perceptions of EBP, research, and clinical practice guidelines. The research was approved by the College's IRB.

\section{Results}

Survey means were compared with the statistical program SPSS using both $t$ Test for Independent Groups and the Mann-Whitney Test with the same results. Therefore, the following data reports only the more commonly used $t$ Test.

The first question was - were the two groups' pre survey results statistically similar? Using a significance level of $\mathrm{p} \geq .05$ the pre survey results showed the control group had a statistically significant higher mean for Q5 ( $\mathrm{p}=$ $.002)$ and for $\mathrm{Q} 6(\mathrm{p}=.03)$. 
An exploration of pre-post results for the control group and the experimental group showed the following.

Table 1

Control Group Pre Post Survey Comparison of Means $(n=16)$

\begin{tabular}{|c|c|c|c|c|c|c|}
\hline \multicolumn{2}{|c|}{ Variables } & \multirow{2}{*}{$\begin{array}{l}\text { Mean } \\
4.3125\end{array}$} & \multirow[t]{2}{*}{$S D$} & \multirow[t]{2}{*}{$t$} & \multirow[t]{2}{*}{$p$} & \multirow[t]{2}{*}{ Effect Size (Cohen's $d$ ) } \\
\hline Q1 & Pre & & & & & \\
\hline & Post & 4.75 & .44721 & -2.671 & $.012 *$ & .24 (small) \\
\hline \multirow[t]{2}{*}{ Q2 } & Pre & 4.375 & .50000 & & & \\
\hline & Post & 4.8125 & .40311 & -2.725 & $.011 *$ & .25 (small) \\
\hline \multirow[t]{2}{*}{ Q3 } & Pre & 4.625 & .71880 & & & \\
\hline & Post & 4.875 & .34157 & -1.257 & .219 & \\
\hline \multirow[t]{2}{*}{ Q4 } & Pre & 4.25 & .44721 & & & \\
\hline & Post & 4.75 & .44721 & -3.162 & $.004 * *$ & .29 (small) \\
\hline \multirow[t]{2}{*}{ Q5 } & Pre & 4.4375 & .51235 & & & \\
\hline & Post & 4.875 & .34157 & -2.842 & $.008 * *$ & .26 (small) \\
\hline \multirow[t]{2}{*}{ Q6 } & Pre & 3.75 & .57735 & & & \\
\hline & Post & 4.3125 & .60208 & -2.697 & $.011 *$ & .25 (small) \\
\hline \multirow[t]{2}{*}{ Q7 } & Pre & 4.1875 & .65511 & & & \\
\hline & Post & 4.5 & .63246 & -1.373 & .180 & \\
\hline
\end{tabular}

Table 2

Experimental Group Pre Post Survey Comparison of Means $(n=17)$

\begin{tabular}{|c|c|c|c|c|c|c|}
\hline \multicolumn{2}{|c|}{ Variables } & Mean & $S D$ & $t$ & $p$ & Effect Size (Cohen's $d$ ) \\
\hline \multirow[t]{2}{*}{ Q1 } & Pre & 3.9412 & .65865 & & & \\
\hline & Post & 4.40 & .63246 & -2.003 & .054 & \\
\hline \multirow[t]{2}{*}{$\mathrm{Q} 2$} & Pre & 4.2941 & .58787 & & & \\
\hline & Post & 4.3125 & .60208 & -.089 & .930 & \\
\hline \multirow[t]{2}{*}{ Q3 } & Pre & 4.4706 & .51450 & & & \\
\hline & Post & 4.5625 & .62915 & -.461 & .648 & \\
\hline \multirow[t]{2}{*}{ Q4 } & Pre & 4.1176 & .60025 & & & \\
\hline & Post & 4.7500 & .44721 & -3.414 & $.002 * *$ & .30 (small) \\
\hline \multirow[t]{2}{*}{ Q5 } & Pre & 3.5882 & .87026 & & & \\
\hline & Post & 4.8000 & .41404 & -4.917 & $.000 * *$ & .44 (moderate) \\
\hline \multirow[t]{2}{*}{ Q6 } & Pre & 3.2941 & .58787 & & & \\
\hline & Post & 4.2500 & .57735 & -4.709 & $.000 * *$ & .42 (moderate) \\
\hline \multirow[t]{2}{*}{ Q7 } & Pre & 3.6471 & .86177 & & & \\
\hline & Post & 4.2500 & .68313 & -2.218 & $.034 *$ & .20 (small) \\
\hline
\end{tabular}

$* p<.05 \quad * * p<.01$ 
Table 3

Comparison of Post Survey Control vs. Experimental Means

\begin{tabular}{ccccccc}
\hline & Variables & Mean & SD & $\boldsymbol{t}$ & $\boldsymbol{p}$ & Effect Size (Cohen's $\boldsymbol{d})$ \\
\hline Q2 & Control & 4.8125 & .40311 & & & \\
& Experimental & 4.3125 & .60208 & 2.760 & $.010 * *$ & .25 (small) \\
\hline$* * p=01$ & & &
\end{tabular}

$* * p=.01$

\section{Discussion}

Clearly both methods improved the student's perceptions and reported use of EBP. There was, however, only a modest difference between the two groups' post survey results with only one question, Q2, showing a statistically significant difference (control higher than experimental). But it is important to remember that the two groups were not statistically equal to begin with, the control group ranking itself higher on Q5 and Q6 before any teaching strategy had begun. Therefore, it is heartening to see the moderate Effect Size increase in the experimental group's pre and post rankings of Q5 and Q6. Finally, only the experimental group showed a statistically significant increase in the ranking of Q7.

Though not a dramatic success I believe the abbreviated approach shows some promise and should be explored further as a teaching technique for undergraduate BSN students.

\section{REFERENCE}

1. Pravikoff, D., Tanner, A., \& Pierce, S. (2005). Readiness of U.S. nurses for evidence-based practice. American Journal of Nursing, 105 (9), 40-51. 